Article

\title{
Domestic Connectivity: Media, Gender and the Domestic Sphere in Kenya
}

\author{
Jessica Gustafsson \\ School of Culture and Education, Södertörn University, 14189 Stockholm, Sweden; E-Mail: jessica.gustafsson@sh.se
}

Submitted: 30 November 2017 | Accepted: 9 May 2018 | Published: 29 June 2018

\begin{abstract}
This article explores how increased media access and use influences Kenyan women's everyday life and alters the domestic space. Based on 30 in-depth interviews with women in Uasin Gishu County, Kenya, the article demonstrates that women have incorporated newly gained media into their daily lives and routines. Increased media access has opened up the home and turned the domestic sphere from a secluded place into a connected space in which women can receive input from, connect with and interact with the world beyond their immediate surroundings whilst simultaneously remaining at home and fulfilling their traditional gender roles. Women's media use thus reinforces their connection to the domestic sphere and the gendered division of labour. Although it has the potential to challenge gender inequalities, the extent to which this occurs depends on the individual woman's ability to act on the imaginaries and ideas that media carry.
\end{abstract}

\section{Keywords}

domestic sphere; gender roles; Kenya; media and everyday life; women's media use

\section{Issue}

This article is part of the issue "Media and Communication between the Local and the Global", edited by Jessica Gustafsson (Södertörn University, Sweden) and Kinga Polynczuk-Alenius (University of Helsinki, Finland).

(C) 2018 by the author; licensee Cogitatio (Lisbon, Portugal). This article is licensed under a Creative Commons Attribution 4.0 International License (CC BY).

\section{Introduction}

Jane is a 22-year-old woman. She grew up in a rural village in Western Kenya, where she lived with her siblings and grandfather as both her parents passed away when she was a young girl. Their house was not connected to electricity, but they had a battery driven radio that the grandfather used to listen to vernacular radio stations on. Sometimes Jane was allowed to switch it to her favourite radio station, Kiss 100, a commercial private radio station in Nairobi, so that she could listen to modern music. Less than a year ago, Jane moved to her aunt's house in a middle-class estate in Eldoret to help look after the aunt's children. Now she can listen to radio whenever she likes, and, since relocating, she has also been exposed to TV for the very first time in her life. She loves TV due to its audio-visual character and content that, according to her, "help her develop". She says that TV teaches her how to live and interact with other people. In other words, it prepares her for life to come. The TV also helps her to look after the children, as they can watch cartoons while she does other household du- ties or while she is busy on her new mobile phone. Her new mobile phone is a Techno touch, a smart phone, which allows her to access the Internet and therefore to chat to her friends and her boyfriend (who lives in Nairobi) using Facebook and WhatsApp (Interview Jane, $16^{\text {th }}$ April 2015).

In the last year, Jane's life has changed dramatically. Not only did she leave a rural setting for a life in the city, but she also had to navigate the increased media access that came with such a move. Even though Jane's domestic responsibilities mean she stays mainly inside the home, she is now exposed and connected to the world outside; locally, regionally and even globally through media. Jane's story illustrates the huge disparities in how people in Kenya live and their access to media. It also draws attention to how the increased introduction of media in people's homes is changing people's-especially women'severyday lifei in the domestic sphere, which is a theme this article will explore.

The use of new technology, such as mobile phones, is currently growing rapidly in Kenya. Consequence, there is a growing interest in how access to new technology can 
help assist development goals and for example bridge gender inequalities. Popular development discourse often paints a very optimistic picture of the appropriation of, for example, mobile telephony. Yet, in order to fully understand this use of media and technology, it is important to situate it in the societal context and existing power structures, as new technology has the potential not only to challenge but also to reinforce existing power structures (Tenhunen, 2013). Moreover, it is important to situate a new technology in the existing local media ecology. Thus, this article examines the increased access to and use of both old and new information and communication technologies (ICTs), since it wishes to emphasise that, in recent years, all women have become more connected to the world beyond their immediate surrounding but that the degree to which this has occurred depends on factors such as their educational level, geographical location and financial situation. Through qualitative interviews with 30 women in Kenya, the article aims to discuss the following question: How does increased access and use of media influence Kenyan women's daily life in the domestic sphere and in what ways does it challenge gender inequalities and prevailing gender roles?

\section{Background and Literature Review}

In order to understand and situate women's media use in Kenya, this section will first discuss gender inequalities in Africa; second, it will deal with theories of media in the domestic sphere and, finally, it will review some relevant literature on media and gender in Africa.

\subsection{Gender Inequalities in Africa}

Gender inequality is often illustrated by the dichotomy between the public and domestic sphere. Traditionally, women in many African countries had the opportunity to partake in public life, even if their involvement was not equal to that of their male counterpart, but this changed with the arrival of colonialism and the introduction of the modern African states (Mikell, 1997, pp. 3-10). With Colonialism and Christianity came the idea of building the home (Mutongi, 1999/2005, p. 73) and women's identities were to a large degree reduced to mothers and domestic dependent wives, as women were discouraged from partaking in activities in the public sphere, for example, agricultural work, in which they had previously engaged (Cornwall, 2005, pp. 7-11). Consequently, women's access to the public realm decreased and space became increasingly gendered. Women's restricted mobility and limited access to public spaces affected women's access to income as well as information and knowledge (Hassanin, 2009, p. 77).

Nowadays, few Kenyan women are formally employed. The majority of women do work, whether in the informal economy or in the household, but their work is often undervalued and "invisible" (Nzomo, 1997, p. 242). Since their income is not always considered part of the household economy, their contributions do not often lead to more decision-making power in the family (Wamue-Ngare \& Njoroge, 2011, pp. 10-11). Moreover, women have triple work burdens due to their domestic, reproductive and productive roles (Nzomo, 1997, p. 247), and only the latter generates income.

Repeated financial slowdowns in the Kenyan economy (Kelbert \& Hossain, 2014; Wamue-Ngare \& Njoroge, 2011) and the HIV/AIDS epidemic (Oburu, 2011, p. 153) have increased the pressure on women to conduct paid labour. As men rarely voluntarily give up their privileges that patriarchy has given them (Nzomo, 1997, p. 236), several studies have shown that changes in family constellations in Kenya, whereby the superiority of the man as the breadwinner and head of the family is challenged, has increased conflicts, divorces, gender-based violence and alcoholism (Kelbert \& Hossain, 2014; Wamue-Ngare \& Njoroge, 2011). Women's gained power thus comes at a high price and, even though they have to engage in paid work, the un-paid work remains.

Gender equality is central in the Kenyan 2010 constitution. However, due to strong prevailing cultural norms and a law passed in 2014 that made polygamythough not polyandry-legal, such gender equality might take time to implement. Moreover, as Josephine Ahikire (2014) states, although several African governments have adopted more liberal forms of feminism and passed national gender policies that aim for gender equality, few resources have been allocated to its implementation. There is therefore a risk that concepts such as gender and empowerment become depoliticised buzzwords (Ahikire, 2014, pp. 11-17).

The dominant perception of womanhood in Kenya is to a large extent synonymous with being caring and motherly (Spronk, 2007, p. 12). Many men perceive modern working women as "out of place" (Kesby, 1999, p. 40) or egocentric (Spronk, 2007, p. 12). In Kenyan popular culture, modern women who challenge traditional gender roles are often labelled immoral. The "city girl" and the "university girl" are two reoccurring stereotypes that are often contrasted with the "pure village girl" in popular discourse (Ligaga, 2014). Thus, women's increased freedom and liberation often receive misogynist responses from conservative men who argue that they are defending "African culture" (Ahikire, 2014, p. 20) by stigmatizing women who break with gender norms as neglecting African customs (Nzomo, 1997, p. 241). Yet, despite this response from men, women continue to explore the available possibilities to challenge the gender structures that are imposed on them in their daily lives (Ahikire, 2014, p. 8).

\subsection{Media in the Domestic Sphere}

Media and communication technologies have the ability to disrupt and reshape the boundaries of different spheres in society. When media enter the home, the dis- 
tinction between private/public is highlighted and simultaneously challenged. Media and communication technologies become embedded in the everyday routines of the household and those who are part of it. However, media can also have a disembbeding effect by facilitating contact between people in the home and those outside (Morley, 2000, pp. 86-87). Morley phrases this effect as the ability to "articulate together that which is separate" (Morley, 2000, p. 87). While sitting on the living room sofa, family members can follow events in other parts of the world on the TV or talk to a friend in a distant place on the phone.

In the 1970s, Raymond Williams (1975) introduced the concept of mobile privatisation to describe this phenomenon. He argued that both the radio and the television facilitated new social input by bringing news and entertainment into the home. These technologies helped people fulfil their wish to discover and see new places while not having to leave the safely of their house. Williams argued that these new technologies were characterised by two contradictory but linked predispositions: mobility on the one hand and more self-sufficient family homes on the other (Williams, 1975, pp. 26-27).

As domestic technologies are embedded in the everyday life of the family, they contribute to the construction and maintenance of gender relations within the family. It is therefore possible to talk about gendered patterns of media usage. For example, in her study, Ann Moyal identified a distinct female usage of the telephone; women utilised the phone for kin keeping and nurturing friendships, thus helping women to create and sustain a network outside their homes (Moyal, 1992, p. 67). Moreover, Lana Rakow and Vija Navarro (1993) found two distinct mobile phone practices among women: remote mothering and working parallel shifts. Remote mothering refers to the ability to always be available to one's children and to be able to fulfil the obligations of a mother across time and space, while working parallel shifts refers to being able to exist simultaneously in the domestic and work sphere (Rakow \& Navarro, 1993). These distinct female media practices have developed due to women's subordinate position. As much as these practices can challenge the restrictions imposed on women's lives, they simultaneously reinforce traditional gender roles.

\subsection{Media and Gender in Africa}

Several studies (Hilbert, 2011; Wamala, 2012) suggest that women in the Global South often have less access to ICTs than men, due to women's restricted access to education, employment and income. It is thus women's position and disadvantages in the societal structure that impact on their access and usage of ICTs (Wamala, 2012, pp. 3-4). It is therefore necessary to adopt an intersectionality approach when analysing women's access and use of media and communication technologies, as factors such as class, race, education and age not only influence women's marginalisation, as Kimberle Crenshaw
(1991) argues, but also their access and use of media and communication technologies.

Mobile phones are being adopted rapidly in Africa, leapfrogging landline telephones, and, even though women still have lower mobile ownership than men in Kenya, the penetration rate is high, even among rural women (Gustafsson \& Nielsen, 2016, 2017). Many studies show that women mainly use their phone to nurture strong ties, i.e. stay connected with family members (Gustafsson \& Nielsen, 2016; Tenhunen, 2008), but research also shows that mobile phones can help women venture into businesses (Tawah, 2013).

After marriage, it is common for women in Kenya to move to the village or the home of the man, and while many men go to work in the city, the wives usually remain to manage the home and the children. The mobile phone therefore becomes a tool that facilitates communication between dispersed family members (Murphy \& Priebe, 2011). Moreover, rural women in Kenya seldom make use of the mobile quality of the mobile phone; they rather use it as a traditional landline (Murphy \& Priebe, 2011). Alette Schoon (2011) argues that the mobile phone actually facilitates immobility, as the phone "make[s] it easier to stay home and get through the day", at least for housebound women in poor areas in South Africa (Schoon, 2011, p. 112).

According to George Gathigi (2009), radio, which is the medium with the largest audience in Kenya, provides women with information and news but also companionship in their daily life in the domestic sphere. His study also demonstrates how radio upholds gendered spaces within the domestic sphere, as men often listen to one radio in the living room, whereas women listen to another radio in the kitchen while preparing food. Moreover, the study suggests that women are more orientated towards health and family programmes because they can relate to the content. One single mother in Gathigi's study felt less abnormal after listening to a programme which discussed single motherhood and women-headed families (Gathigi, 2009).

Similarly, Lila Abu-Lughod (1997) and Bodil Fredriksen (2000) demonstrate in their work how women in Egypt and Kenya use TV content to reflect on their lives, prevailing gender structures and their own position within those structures. Both studies draw on Appadurai's (1990) idea that media offers new imaginaries, new ways for the audience to see and imagine their reality. The findings of these studies underline the importance of situating women's media use in their everyday life setting and within a wider societal context.

\section{Methodology-Studying Women's Media Use in the Domestic Sphere}

The present study is based on semi-structured in-depth interviews and was carried out between January and June 2015 in three different locations in Uasin Gishu County, Kenya. The previous year a baseline survey with 
799 households had been conducted in five areas (two rural settings, two peri-urban and different parts of the city of Eldoret) to better understand people's media access and use. Some of the most prevalent results were significant differences in media access and use between men and women but also between people living in rural, urban and peri-urban areas and how these intersected. Consequently, the qualitative study, which this is part of, aimed to explore these differences. The interviews were conducted in some of the same areas as the baseline study had been carried out as one rural area, one periurban area, and two locations in the city of Eldoret were selected. In each location, the local administration, the chief and the village elders permitted access.

Approximately the equivalent of one month was spent in each location and the first few days were devoted to general observations of the area and its media situation and informal conversations with people. However, observation was not a major data collecting method but a complement that was used to better understand the areas and help achieve diversity in the sampling process as it provided knowledge about who lived or spent time in which places.

After the initial phase, individuals living in the area were interviewed. Semi-structured in-depth interviews were chosen, as it is a method that allows the interviewee to influence the direction of the interview and generates in-depth nuanced understandings of the subject studied (Kvale, 1997). The interviews discussed which media (old and new) the women had access to and used, which type of content they preferred and how media use was integrated in their daily life. The interview guide consisted of general questions like "What do you normally like to watch on TV?" "What do you use your mobile phone for?", "Who do you normally communicate with?" - questions that were followed up by probing questions to better understand how and why they used media in a certain way and the meanings they ascribed to their media use. All interviews were conducted with an interpreter present to enable the interviewees to express themselves in Kiswahili or Kalenjin in addition to English.

In total, 30 interviews with women were conducted; most often in or in close proximity to the interviewee's home, for example in their compound or on their plot, unless the interviewee was working in the area and it was more convenient to conduct the interview at the workplace while on break. 10 interviews were conducted in a rural area, 10 interviews were conducted in the city of Eldoret (half of these interviews took place in an informal settlement and half in a middle-class estate), and the remaining 10 interviews were conducted in a periurban area-bringing different female experiences together. The interviewees were purposefully sampled according to theoretical indices, thus aiming to achieve diversity in terms of age, financial status, geographical setting and education; however, the study does not aim nor claim to be representative. No concrete checklist was used to select interviewees, but when approaching potential interviewees, these categories were in the back of our mind. One factor for example that influenced the selection of which people we approached was the type of housing they lived in-ranging from bricked houses with satellite dishes to mud huts without electricity, as it influences the household's media use. Moreover, the type of house they lived in often corresponded with their financial status and thus often also influenced level of education. Age was another category which were considered when approaching who to interview, yet sometimes it was difficult to estimate someone's age and if they agreed to be interviewed we did not decline due to them being a few years younger or older than we had anticipated. In the rural area, five women below 30 (18-29) and five above 30 years (30-72) were interviewed. In the other two areas, we interviewed six women under 30 and four above 30 .

The interviews were recorded with the consent of the interviewee and ranged between 45 minutes to 2 hours in length and have been transcribed and translated into English if conducted in Kiswahili or Kalenjin. The names of the interviewees have been changed to better protect their identity.

First, each interview transcript was read repeatedly to gain an overview of the material, which was then structured according to different media through a simple paste and copy process. Next, each medium was broken down thematically by identifying content-based themes through open coding. By cross reading the material, it became apparent that, on a more conceptual level, many of the content-based themes corresponded across media platforms. For example, both TV and radio were regarded as important for keeping up-to-date with world news but also for their ability to teach the women about various topics (about family life and relationships in particular). Through these cross readings, three overarching conceptual themes were constructed, and it is these themes that will form the basis of this article: "Letting the world into the home", "Maintaining and deepening strong ties" and "Financial and cultural barriers to women's media consumption".

\section{Analysis: Women and Media in the Domestic Sphere}

The following section will first analyse women's use and experience of media around the three conceptual themes mentioned above, and, second, it will discuss the findings in relation to the concepts of domestic connectivity and intersectionality.

\subsection{Letting the World into the Home}

Ivy, a 25-year-old married mother, lives with one child and husband, who is a welder, in an informal settlement in Eldoret. Finances are often the cause of arguments in their relationship and, according to Ivy, her husband "has a light hand". To avoid arguments 
and ensure that the daughter and her have enough to eat, she realised that she needed to start earning money. Through a programme on Citizen Radio she came to "the realisation that women can also do business" and she started a fish business. Instead of having a stall, she operates the business from home using her mobile phone to communicate with the fish market and customers, thus she can look after her daughter and the home at the same time. She also uses her mobile phone to save and send money to her sister through Mpesa and to organise the Chama (table banking) that she has together with other women; this also acts as a safety net because the Chama offers loans. Their house has a TV, and Ivy, who loves Afro Cinema, has organised her busy daily schedule around it: "between $2 \mathrm{pm}$ and $3 \mathrm{pm}$ I watch and when the time comes I go back to work" and "from $9 \mathrm{pm}$ I can watch until $11 \mathrm{pm}$ when I go to sleep". Through her phone, she also accesses Facebook and she says, "Facebook I love because of friendships". She explains that she even has Facebook friends in South Arabia and how they discuss life. It is clear that Ivy is not happy in her marriage and has considered leaving but has decided to persevere (Interview Ivy, $13^{\text {th }}$ April 2015).

Ivy is very connected. She has access to radio, TV, a mobile phone and social media. Her story highlights several aspects of how media is letting the world into the home (which I discuss further below): Mobile phones have helped women start up income-generating activities in the proximity of the home, thus not interfering significantly with their household duties. Media content comes with ideas and teaching that women can apply in their lives, and it provides much-needed relaxation and escapism. The phone is used to maintain a network outside the house, be it family, the local Chama or distant friends on Facebook.

The mobile phone assists many women to run businesses from home. Similar to Ivy, the phone helps Eda, 28, peri-urban, run her small tailoring business from home while taking care of her children. Another woman, Bee, who is 19 years old and lives with her grandmother in a rural area, braids women's hair in a room in their compound. Bee uses her mobile phone to communicate with her customers, which means that she does not have to sit and wait for customers and can take care of her 9-month-old baby. The mobile thus enables women to conduct paid work from home-turning the home into a workplace, not only for unpaid domestic work but also for paid work, which resonates with Rakow and Navarro's (1993) concept of working parallel shifts. The mobile thus help women overcome the fact that their restricted mobility often have negative impact on their income (Hassanin, 2009). In recent decades, women in Kenya have been forced to take on more financial responsibilities (Kelbert \& Hossain, 2014; Wamue-Ngare \& Njoroge, 2011). Sylvia Chant (2006) calls this phenomenon the feminization of responsibilities and obligations to stress that the increased burden placed on women does not increased their power within the household.

Due to the deregulation of the media market in Kenya in the 1990s and the fact that TV and radio sets have become cheaper, news and entertainment in many different forms have entered into many Kenyan homes. Radio is still very important in Kenya (Gathigi, 2009) and it allows women to stay updated on the world outside the home, while simultaneously fulfilling their obligations as women or running small businesses inside the home or in the close proximity of the compound, since the radio is portable. TV, which is appealing due to its audio-visual character has changed the perception of the world:

Let us say the president, we didn't know at first what he looked like. But after the TV we knew if he's short or tall or how he talks, everyone we saw on TV, we saw other countries, how they were doing there, different from us, we saw many things. (Grace, 50s, peri-urban)

Grace is a married shop owner who lives on her own as her husband decided to relocate to the rural once retiring. They bought a TV 20 years ago and Grace feels it has reduced her sense of place, since she can see and experience distant places and cultures. TV also keeps women company and entertained, and several women stresses that, since acquiring a TV, they stay up later and that "the house is very quiet without a TV"-emphasising that TV has become an essential part of everyday life in their households. Noni, a single mother who runs a hair salon near her house bought her first TV two years ago, suggests that TV offers a form of escapism, a needed break:

Like sometimes maybe you're tired, your day didn't go well, when you're seated there and watching the soap opera, it's good. (Noni, 33, peri-urban)

Latin American soap operas and Afro cinema are popular among the women in the study. The soaps and series do not only offer escape and entertainment; almost all the women interviewed said that they watch because the programmes can teach them somethinglessons they can apply in their everyday life. In other words, media content carries new imaginaries (Appadurai, 1990), which help women reflect on their own reality from new perspectives.

Kate is a 22-year-old student at Moi University. She is expecting her first child in less than a month, which means that she will have to take a break from her studies. One year ago, she got her first TV and she recites the story of a woman called Maricruz, who is the main female character in her favourite Mexican soap. Maricruz comes from a poor family but falls in love with a wealthy man. According to Kate, the story has a moral lesson that she finds useful in her own life: 
So, I learnt that it is good to forgive and move on with your life and there is always something good at the end of every bad experience. (Kate, 22, peri-urban)

Many women also state that they like to listen to radio due to the discussions about family life and relationships, which Gathigi's (2009) study supports. These discussions function as a public forum where family values and gender roles are discussed and negotiated:

Like yesterday, they were discussing a matter of a girl. She had just given birth to a baby; the guy didn't want to take responsibility so the girl struggled with the baby. By the time the baby was six months, the guy wanted to come back so the girl was asking people to help her decide what to do. So, I learnt that if a guy doesn't want to take responsibility for a child, you can take care of your child and take the precautions with the government where they help you get the custody of the child. (Eli, 23, peri-urban)

By listening to this discussion, Eli learnt about her rights as a woman. Eli is a single mother to a three-year-old boy, so the discussion had parallels with her own life situation. To use media content as an entry point to reflect on one's own life situation and gender relations is something which previous studies has pointed to (Abu-Lughod, 1997; Fredriksen, 2000). In this case, media content function as support, by emphasising that others are going through similar difficulties, but also as an eye-opener by exposing women to new imaginaries (Appadurai 1990). In this instance, ideas that challenge the norm of the traditional family headed by a man. Apart from listening to radio and watching soap operas (at friends' houses, because she has no TV of her own), Eli started to use her mobile phone to access the Internet and social media when she joined university one and half years ago. Higher education has introduced several women, especially university students, to the Internet since it has become a mandatory tool to access information for school projects. Yet, for many women, the Internet is still a mystery that they do not engage with, something that they have yet to grasp how to use or how it can benefit them. This is reflected by the fact that, out of all the women with Internet-enabled phones in rural areas, only one uses the phone to browse online; the other women do not browse since they do not know how, which stress that knowledge is an important dimension of access.

Once browsing the Internet becomes part of the women's daily routine, it opens up a new information channel and new ways to experience and interact with the outside world. Women in this study go online to read celebrity gossip, discover the latest news, find job or education opportunities, and access health information:

I've googled a lot, maybe concerning some information, maybe concerning some news, maybe breaking news, maybe I want to take care of the baby, devel- opment of a child or, or even maybe I have some symptoms of some illness I can just check some symptoms and just see which sickness....Yeah, knowledge, information-any part of the world you want to know you just Google. (Lily, 31, urban, middle class estate)

Lily, who is on parental leave from her job at a bank, feels that knowledge about anything or any part of the world is available to her since she started accessing the Internet five years ago; you just have to google it. Google has thus emerged as an alternative source of information, a complement to traditional circles of knowledge sharing, such as female relatives, who traditionally had a privileged standing on issues like child nursing. Similarly, Noni, who has used the Internet for three years, stresses how Google assists her in her job as a hairdresser:

Let's say mostly, I google maybe when I need to know something, like there was a mama who came and told me that her hair was falling out...then I always Google knowing how to treat it. (Noni, 33, peri-urban)

The Internet provides useful information to these women. By accessing the Internet using their mobile phone, which is by far the most common way of accessing Internet, they can retrieve information and get answers to many questions. The Internet thus brings a database of information into their homes, information that was previously difficult to attain. As these quotations suggest, the Internet is often synonymous with the search engine Google; moreover, it is clear that the women fully trust Google and thus lack critical media literacy. Apart from Google, social media platforms such as Facebook are also popular among Internet connected women in this study, as they help maintain friendship and make new friends, as the story of Ivy illustrated.

\subsection{Maintaining and Deepening Strong Ties}

Media open up the home to the world outside and enable connectivity, yet media also strengthen women's strong ties and their connection with their natal homes, stressing media's disembedding and embedding effects (Morley, 2000). Many married women are dislocated due to rural-urban migration or marriage:

What I love the most is the vernacular....You know, when I listen to that I feel like I'm at home [laughs]. (Eda, 28, peri-urban)

Eda and her husband moved to another part of Kenya because of her husband's work. Throughout the interview, it is clear that Eda misses home, but, by listening to radio stations that broadcast in her mother tongue, she feels in touch with home. Other women prefer vernacular radio stations because they broadcast in the language that they are most fluent in, and this helps them maintain their language and pass it on to their children: 
There are these programmes that discuss past events, maybe things to do with Kalenjin, you know sometimes it is good to remind yourself of how to speak Kalenjin because you can speak so much Swahili that you forget the vernacular, so we teach ourselves and the children. (Terry, 41, peri-urban)

For Terry, listening to vernacular radio is to nurture part of her identity and past. One could thus argue that vernacular radio is important for these women's identity construction. Kesby (1999) states that women's physical dislocation due to marriage influences their identity and sense of "otherness". Listening to these radio stations is thus a way to carry some of their past with them into their new life. Women's mobile phone usage also reflects their wish to stay connected with their natal families:

Interviewer: And whom do you normally talk to on the phone?

Ann, 27, urban: My relatives...relatives, people that you love.

Jemutai, 26, rural: I bought the phone so that I could talk to my parents....It brings us together as a family, also with our other family who are in Maasai, we talk sometimes, and because we can't always reach them we talk on the phone.

For Ann and Jemutai, who got their first mobile phones three and six years ago respectively, the phone makes it easy to stay connected more regularly with relatives, which strengthens family ties despite physically distance. This contact also helps increase a sense of security and emotional support as family members are only a phone call away (Tenhunen, 2008).

The phone also helps the women maintain and co-ordinate family life between spouses (Gustafsson \& Nielsen, 2016; Murphy \& Priebe, 2011). Cheru is a 19year-old married mother, who has moved to her husband's family home in a small village. Since job opportunities are few in the rural, the husband has moved to Nairobi to work as a guard, but he bought Cheru a phone so they can communicate. They speak daily on the phone, which makes her feel "like he [her husband] is around". Mobile phone thus helps reduce distance between dispersed family members (Kesby, 1999; Murphy \& Priebe, 2011). Cheru's phone is Internet-enabled but she does not know how to browse.

\subsection{Financial and Cultural Barriers to Women's Media Consumption}

Robson (2000) argues that "women's access to goods and resources in various societies is frequently constrained by their mobility and associated gender roles" (p. 180). This is true in Kenya, especially for women in the rural areas. Unless women have access to a TV in their homestead, they rarely watch TV as cultural norms restricts women's public TV watching:

No, we don't go to the shopping centre to do that, it's only men who are used to that, they watch football and come at night but for girls it's not allowed, it's not good....According to our culture, you don't find girls going to the shopping centre to watch TV, it sounds awkward and irresponsible, how do you just, you know you are a woman you also have other duties to help with your mother doing household chores, when it reaches evening that is when the boys go to the shopping centre to watch, but for girls, no, it is not allowed actually. (Dede, 30s, peri-urban)

In fact, none of the women in this study have watched TV in a public place, which illustrates how deeply rooted this custom is and how women have internalised the ideal of womanhood as caring and motherly (Spronk, 2007) and how their restricted mobility influence women's access to information and knowledge (Hassanin, 2009). As a result of this norm, coupled with the fact that not all households have a TV, some women in the rural areas have only watched TV a few times in their entire life. In February 2015 , the Kenyan government switched off the analogue TV signal. To receive the digital signals, one needs a decoder, which many households cannot afford to buy. This digital migration has affected women significantly because, unlike their male counterparts, they cannot go to commercial places to watch TV:

Grace, 50s, peri-urban: It has affected me a lot...because I'm alone in this house and TV was something that kept me busy after supper. I could watch even up to $10 \mathrm{pm}$, but now I can go to sleep earlier because I don't have anything to keep me busy...

Interviewer: And do you have any plans to buy the decoder?

Grace, 50s, peri-urban: Yes! I had planned because I was paying school fees for my child I said let me pay this school fees after that I will buy the decoder, yes, I want.

For Grace, as for many women with a TV, buying a decoder is a high priority, but seldom the highest. Finding the money to purchase a decoder might be difficult when other financial obligations are more important, and women are rarely in charge of the family's economy (unless they are single, which often means that the finances are even more constrained). Poor finances also prevent women from replacing broken or lost media apparatus:

Joy, 31, urban, informal settlement: I can't stay without a phone....Because I have many children in school I have to pay school fees first and then save up for the phone. 
Caroline, 53, rural: I used it for a short time then my son got the phone.... used it for phoning, the radio and to watch videos that the kids had put there....I did not expect my son to sell the phone. Interviewer: So why did you give the phone to your son?

Caroline, 53, rural: Because he was not staying at home so I decided to give the phone to him to use....but he sold it to pay school fees.

Many women ascribe importance to media, whether it is to stay updated, be entertained, enable contact with loved ones or meet new people; however, strained household finances occasionally force them to sell a phone or prevent them from replacing a broken radio or lost phone. Thus, women's financial situation and prevailing gender norms influence women's media access and use.

\section{Domestic Connectivity and Intersectionality: Understanding Women's Access and Use}

In Kenya, women's connectivity has increased over the last decade. Today, more women than ever before have access to mobile phones, TV, radio and some even to the Internet and social media. This study shows that the women interviewed have incorporated media into their daily lives and adjusted their daily routines around media, which have been ascribed with meanings in their lives.

As Morley (2000) argues, domestic media stress and can alter the distinction between private and public. However, social space and the distinction between public and private is not only socially constructed; it is also often gendered (Robson, 2000, pp. 179-180). For women in this study, who, due to cultural norms and domestic duties, are often bound to the home, media opens up the home to inputs from the outside world. Images and sounds from all over the world enter the home through the TV and radio (sounds), the mobile phone brings people in distant places "closer", and Google provides some women with information that was previously difficult to attain, at least without leaving the house. Moreover, the mobile phone has, in line with what Rakow and Navarro (1993) calls working parallel shifts, helped some women venture into income-generating businesses that they can run from home while simultaneously conducting their unpaid work as mothers and wives.

Media content, especially soap operas and radio discussions about relationships, allow women to reflect on their own situation and existing gender roles. Through media, women are exposed to new imaginaries (Appadurai, 1990)-different ideas about marriages and family life, which can help them to form their own ideas of what it means to be a woman or a wife today. In the long run, these changes might challenge norms, and women who embrace modern life and enjoy greater mobility might no longer be perceived as immoral (Spronk, 2007).
Presently, the prevailing societal norms moralise these women and these norms are often internalised and upheld by the women themselves. This is illustrated by the fact that it is unthinkable for all the women in this study to watch TV in a public place.

The fact that media, whether a vernacular radio or a mobile phone, help women feel in touch with their natal homes is important for their identity construction (Kesby, 1999) and sense of security (Tenhunen, 2008). Having your mother just a phone call away to provide moral support seems to be very liberating for many women, who, through marriage or rural-urban migration, have been physically displaced, since it arguably helps them to navigate their new roles and settings. Although it could be argued that women using their mobile phone to nurture strong family ties reinforces gender roles, this could still be perceived as an outward looking practice, since the regular contact the mobile phone enables is a new additional routine in women's everyday lives that helps them stay connected.

Williams (1975) developed the concept of mobile privatisation in the 1970s to describe how homes in West were changing, partly due to increased media access. Half a century later, homes in Uasin Gishu, Kenya, are now changing in a similar way. Due to women's restricted mobility in Kenya, using the word "mobile", even though it refers to mobility of the mind, risks communicating a wrong impression of their situation. The mobile phone for example is often, especially in the rural areas, mainly used as a landline, which facilitates regular communication with dispersed family members. In other words, it helps them nurture strong ties and makes mobility and travel less essential. Increased media access has not necessarily improved women's physical mobility, rather it has helped them to better cope with their immobility by being able to stay connected with the world without leaving the domestic sphere; which is also something which Schoon (2011) underlines in relation to women in South Africa.

In other words, domestic connectivity is a phrase that better captures the experience of women included in this study, as it both stresses their confinement to the home and their increased connectivity. Communication technologies become means to receive input from the outside and connect with new spheres, whether this is being part of networks outside the home or working whilst also managing their traditional gender roles as caring mothers and the head of household duties. Increased media access has therefore not only changed everyday life for these women; it has also altered the domestic space, turning it from a secluded into a connected space.

The concept of domestic connectivity highlights the interesting interplay between media usage, (im)mobility and domestic bonds. It should be situated in relation to women's everyday lives and media situations, as new media technology might impact differently on a rural woman's everyday life than on an urban woman's everyday life, since urban women often enjoy greater mobility. 
Yet it is important not to perceive domestic connectivity as something static that can be concretely measured. Women's media situation, their bonds to the domestic sphere and connections with the world outside are influenced by several conditions, which, to some degree are fluid and can change, whether this is due to increased media access, changing gender roles or rural-urban migration, as the story of Jane illustrated at the beginning of this article.

Yet, this study also reveals huge disparities in women's media access and use in Kenya. Crenshaw (1991) suggests that, in order to better understand the marginalisation of women, it is not enough to merely discuss women as a homogenous group. Women's experiences of the patriarchal structure depend on factors such as education, class, race and age, as these intersect with gender. The concept of intersectionality is thus useful when discussing Kenyan women's access and use of media and technology and the impact it has on their everyday lives.

One factor that tends to most influence media access and use is whether women live in urban or rural areas, precisely because it intersects with education, income and increased life choices and opportunities. More women in the urban areas are educated. Many might have grown up in rural areas and moved to urban centres to access higher education and, once they have completed the education, few consider moving back because income-generating opportunities are greater in the urban areas and life there is less restricted as traditional gender roles, although still present, are less prevalent. This is true for women even if they lack higher education. In urban areas, there are more opportunities to run a business as a woman, and society is less condemning if you find yourself as a single mother.

So where do media fit into the picture? Overall, urban women have higher access to media technologies. One obvious factor is better access to electricity. Moreover, due to the increased opportunity to run a business, it is easier for women like Ivy to be inspired by a radio show and start running a business from her home using her mobile phone to communicate with customers. Once the business is profitable, Ivy has the financial independence needed to upgrade her phone to one that can access the Internet, the skills to use the technology, and the financial means that is required to use those services.

Similarly, it is easier for a woman like Eli to feel empowered by the knowledge that she can get custody of her child if required, as she soon will have a university degree and is planning to move back to Nairobi, an area where social norms are less restricting. Thus, factors such as education, financial situation and geographical location not only influence the media you have access to but also influence how you can realise the wider imaginaries that media content and connectivity offers.

In other words, media's ability to challenge gender inequalities is far from direct and revolutionary. This is also implied by the term "domestic connectivity", as it empha- sises the tendency for women to be bound to the domestic realm. It is true that media offer new perspectives, relaxation, enhanced communication and escapism, but it is also true that women use media in a manner that does not interfere with their duties as mothers and wives. Therefore, their media use does not challenge the gendered division of labour. One could even suggest that it in fact reinforces it, yet another possible interpretation is that women use the new technology that is available to them to improve their everyday lives within the boundaries that society and prevailing gender norms impose.

\section{Conclusion}

This study draws attention to the present changes in women's media habits and argues that media can simultaneously have disembedding and embedding effects (Morley, 2000). Media help women transcend the boundaries of the private and public sphere by opening up the domestic sphere to external input, yet, at the same time, media facilitate the maintenance of strong ties and make immobility less of a restriction. The article introduces the concept domestic connectivity to stress and highlight this ambiguity.

This study suggests that media use often confirms and conforms to-rather than challenges-the gendered separation of the private and public and the division of labour which suggest that new information technologies are far from the quick fix that popular development discourse sometimes suggests. Thus, the results of this study have relevance beyond Kenya by showing that in order to better understand the interrelation between media use and gender roles and norms, it is imperative to situate media use in women's everyday life and given social context and take into account how factors such as education, income, their rural/urban location influence not only women's access to media but also their ability to act out their gained perspectives and knowledge or imaginaries (Appadurai, 1990). Moreover, it highlights the importance of moving away from single media studies and rather looking at women's entire media ecology.

\section{Conflict of Interests}

The author declares no conflict of interests.

\section{References}

Abu-Lughod, L. (1997). The interpretation of culture(s) after television. Representations, 59(Summer), 109-134.

Ahikire, J. (2014). African feminism in context: Reflections on the legitimation battles, victories and reversals. Feminist Africa, 19, 7-23.

Appadurai, A. (1990). Disjuncture and difference in the global culture economy. Theory, Culture \& Society, 7, 295-310.

Chant, S. (2006). Re-thinking the "feminization of 
poverty" in relation to aggregated gender indices. Journal of Human Development, 7(2), 201-220.

Cornwall, A. (2005). Introduction: Perspectives on gender in Africa. In A. Cornwall (Ed.), Readings in gender in Africa (pp. 1-19). Bloomington and Indianapolis, IN: Indiana University Press.

Crenshaw, K. (1991). Mapping the margins: Intersectionality, identity politics, and violence against women of color. Stanford Law Review, 43(6), 1241-1299.

Frederiksen, B. (2000). Popular culture, gender relations and the democratization of everyday life in Kenya. Journal of Southern African Studies, 26(2), 209-222.

Gathigi, G. (2009). Radio listening habits among rural audiences: An ethnographic study of Kieni west division in Central Kenya. (Doctoral dissertation). Athens, $\mathrm{OH}$ : Scripps College of Communication of Ohio University.

Gustafsson, J., \& Nielsen, P. E. (2016). Challenging or reinforcing the gender divide?-The appropriation of media and ICT in Uasin Gishu, Kenya. In J. Wilson \& N. D. Gapsiso (Eds.), Overcoming gender inequalities through technology integration (pp. 68-92). Hershey, PA: IGI Global.

Gustafsson, J., \& Nielsen. P. E. (2017). Changing communication ecologies in rural, peri-urban and urban Kenya. Journal of African Media Studies, 9(2), 291-306.

Hassanin, L. (2009). An alternative public space for women: The potential of ICT. In I. Buskens \& A. Webb (Eds.), African Women and ICTs. Investigating technology, gender and empowerment (pp. 77-87). London and New York, NY: Zed Books.

Hilbert, M. (2011). Digital gender divide or technologically empowered women in developing countries? A typical case of lies, damned lies, and statistics. Women's Studies International Forum, 34, 479-489.

Kelbert, A., \& Hossain, N. (2014). Poor man's patriarchy: gender roles and global crises. IDS Bulletin, 45(1), 20-28.

Kesby, M. (1999). Locating and dislocating genderin rural Zimbabwe: The making of space and the texturing of bodies. Gender, Place \& Culture: A Journal of Feminist Geography, 6(1), 27-47.

Kvale, S. (1997). Den kvalitativa forskningsintervjun [The qualitative research interview]. Lund: Studentlitteratur.

Ligaga, D. (2014). Mapping emerging constructions of good time girls in Kenyan popular media. Journal of African Cultural Studies, 26(3), 249-261.

Mikell, G. (1997). Introduction. In G. Mikell (Ed.), African feminism: The politics of survival in Sub-Saharan Africa (pp. 1-50). Pennsylvania, PA: University of Pennsylvania Press.

Morley, D. (2000). Home territories: Media, mobility and identity. London: Routledge.

Moyal, A. (1992). The gendered use of the telephone: An Australian case study. Media, Culture and Society,
14(1), 51-72.

Murphy, L., \& Priebe, A. (2011). My co-wife can borrow my mobile phone! Gendered Geographies of cell phone usage and significance for rural Kenyans. Gender, Technology and Development, 15(1), 1-23.

Mutongi, K. (2005). Worries of the heart-Widowed mothers, daughters \& masculinities in Maragoli, Western Kenya, 1940-60. In A. Cornwall (Ed.), Readings in gender in Africa (pp. 71-80). Bloomington \& Indianapolis, IN: Indiana University Press. (Original work published 1999)

Nzomo, M. (1997). Kenyan women in politics and public decision making. In G. Mikell (Ed.), African feminism: The politics of survival in Sub-Saharan Africa (pp. 232-254). Pennsylvania, PA: University of Pennsylvania Press.

Oburu, P. O. (2011). Attributions and attitudes of mothers and fathers in Kenya. Parenting: Science and Practice, 11, 152-162.

Rakow, L., \& Navarro, V. (1993). Remote mothering and the parallel shift: Women meet the cellular telephone. Critical Studies in Mass Communication, 10(1993), 144-157.

Robson, E. (2000). Wife seclusion and the spatial praxis of gender ideology in Nigerian Hausaland. Gender, Place \& Culture: A Journal of Feminist Geography, $7(2), 179-199$.

Schoon, A. J. (2011). Raw phones: The domestication of mobile phones among young adults in Hooggenoeg, Grahamstown, (Master thesis), Rhodes University, Grahamstown, South Africa.

Spronk, R. (2007). The young and the ambitious in Nairobi: Sexuality and emerging middle class selfdefinitions. Retrieved from http://www.ascleiden.nl/ Pdf/paperspronk.pdf

Tawah, S. (2013). Market women and mobile phones in the North West region of Cameroon: Market livelihoods and trade routes through mobile phones. Suomen Antropologi: Journal of the Finnish Anthropological Society, 38(1), 59-82.

Tenhunen, S. (2008). Mobile technology in the village: ICTs, culture, and social logistics in India. Journal of the Royal Anthropological Institute, 14, 515-534.

Tenhunen, S. (2013). Introduction. Suomen Antropologi: Journal of the Finnish Anthropological Society, 38(1), 4-11.

Wamala, C. (2012). Empowering women through ICT (Spider ICT4D Series No. 4 | 2012). Retrieved from http:// www.fao.org/e-agriculture/sites/default/files/uploads /media/Empowering women through ict.pdf

Wamue-Ngare, G., \& Njoroge, N. (2011). Gender paradigm shift within the family structure in Kiambu, Kenya. African Journal of Social Sciences, 1(3), 10-20.

Williams, R. (1975). Television: Technology and cultural form. New York, NY: Schocken Books. 


\section{About the Author}

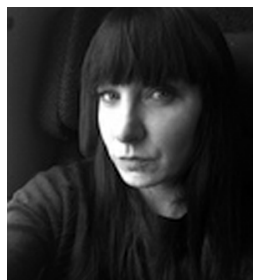

Jessica Gustafsson is a senior lecture in Media Studies at Södertörn University, Sweden. She recently finished her post doc fellowship within the Nordic-Kenyan research project Critical Perspective on the Appropriation of New Media and Processes of Social Change in the Global South at Aarhus University, Denmark. She holds a PhD in Media Studies from Department of Media Studies, Stockholm University, Sweden. 